\title{
IMPLEMENTASI E-SERVICES UNTUK LEGALISIR IJAZAH DAN TRANSKRIP NILAI PADA UNIVERSITAS BUDI LUHUR
}

\author{
Wahyu Pramusinto ${ }^{1}$, Sri Mulyati ${ }^{2}$, Safrina Amini ${ }^{3}$ \\ ${ }^{1}$ Fakultas Teknologi Informasi, Manajemen Informasi, Universitas Budi Luhur, Jakarta, Indonesia \\ ${ }^{2,3}$ Fakultas Teknologi Informasi, Teknik Informatika, Universitas Budi Luhur, Jakarta, Indonesia \\ Email: ${ }^{1 *}$ wahyu.pramusinto@ budiluhur.ac.id, ${ }^{2}$ sri.mulyati@budiluhur.ac.id, ${ }^{3}$ safrina.amini@ budiluhur.ac.id
}

\begin{abstract}
Abstrak - Untuk melamar pekerjaan, alumni Universitas Budi Luhur membutuhkan legalisir ijazah dan transkrip nilai. Untuk mendapatkan legalisir, alumni harus ke datang ke Universitas Budi Luhur dengan membawa ijazah dan transkrip nilai asli untuk digandakan oleh BAAK. Kemudian alumni harus membayar biaya legalisir sesuai dengan jumlah legalisir yang diinginkan. Selanjutnya BAAK meminta tanda tangan Dekan dan memberikan stempel basah di atas dokumen hasil penggandaan. Setelah selesai, staf BAAK menginfokan alumni untuk datang kembali ke kampus mengambil hasil legalisir. Bagi alumni yang berada di luar kota dan yang sudah bekerja, proses ini tidaklah efisien dan memberatkan karena harus mendapatkan izin dari kantor minimal 2 kali untuk melakukan legalisir, yaitu pada saat mengajukan legalisir dan ketika mengambil dokumen hasil legalisir. Untuk memudahkan proses layanan legalisir ijazah dan transkrip nilai bagi alumni tersebut, dibuatlah sebuah sistem layanan elektronik (e-services) sehingga alumni bisa melakukan proses tersebut melalui website. Alumni bisa melakukan pemesanan layanan legalisir melalui website sehingga mereka tidak perlu datang ke kampus. Dokumen hasil legalisir pun bisa dikirimkan ke alamat alumni menggunakan layanan ekspedisi. Penelitian ini bertujuan untuk mengimplementasikan $e$-services berbasis website untuk layanan legalisir ijazah dan transkrip nilai, yang memudahkan alumni dalam hal pengajuan legalisir, dan juga memudahkan staf BAAK dalam menginformasikan status pengajuan legalisir alumni. Hasil dari penelitian ini adalah sebuah aplikasi berbasis website yang dapat digunakan oleh alumni untuk melegalisir ijazah dan transkrip nilai, sebagai bagian dari peran Universitas Budi Luhur dalam melayani alumninya, di mana pun alumninya berada. Aplikasi yang dibuat menggunakan Bahasa pemrograman PHP dan database MariaDB
\end{abstract}

Kata Kunci: e-services, legalisir ijazah, layanan online, legalisir transkrip nilai, website

\begin{abstract}
To apply for a job, Budi Luhur University alumni need legalized diplomas and transcripts. To get legalized, alumni must come to Budi Luhur University with their original diploma and transcripts to be duplicated by BAAK. Then the alumni must pay the legalization fee in accordance with the desired legalized amount. Then BAAK asked for the Dean's signature and also gave a wet stamp on the document resulting from the duplication process. After finish, BAAK staff will inform the alumni to come back to campus to collect the legalized results. For alumni who are outside the city, this process is inefficient and burdensome for alumni who have worked because they have to get permission from the office first, at least 2 times to do legalization, namely when applying for legalization and when taking the legalized documents. To facilitate the process of legalizing diplomas and transcripts for alumni, an e-services system was created so that alumni can carry out the process through the website. Alumni can order legalized services through the website so they don't have to come to campus. This study aims to implement website-based e-services for diploma legalization services and grade transcripts, which makes it easier for alumni to apply for legalization, and also makes it easier for BAAK staff to inform the status of alumni legalization applications. The result of this research is a website-based application that can be used by alumni to legalize diplomas and transcripts, as part of the role of Budi Luhur University in serving its alumni, wherever the alumni are located. Applications created using the PHP programming language and MariaDB database.
\end{abstract}

Keywords: e-services, legalized diploma, online services, legalize grade transcripts, website

\section{PENDAhULUAN}

Perkembangan teknologi informasi yang semakin pesat membuat banyak perusahaan mengubah layanannya dari layanan konvensional menjadi layanan elektronik atau yang disebut e-services. Layanan elektronik ini semakin berkembang seiring dengan semakin mudahnya untuk mendapatkan akses internet. Di bulan November 2020 jumlah pengguna internet mencapai 196,7 juta dengan jumlah pengguna terbanyak ada di Pulau Jawa [1]. Faktor yang mendukung penerapan e-service adalah kepemimpinan dan perkembangan teknologi komunikasi. Peran pemimpin turut menjadi kunci dalam keberhasilan pengembangan e-government terutama dalam memotivasi bawahannya. Selain faktor pendukung, ada juga beberapa faktor penghambat penerapan e-service yaitu infrastruktur teknologi informasi dan sumber daya manusia [2].

Fungsi dan peran Perguruan Tinggi tidak hanya ketika mahasiswa masih aktif dalam perkuliahan atau sebelum lulus. Namun, pasca mahasiswa dinyatakan lulus, perguruan tinggi masih diperlukan layanan dan kontribusinya, di antaranya dalam melakukan verifikasi dan legalisasi dokumen yang dikeluarkannya, terutama ijazah dan transkip akademik [3]. Universitas Budi Luhur juga melayani para alumni untuk melakukan legalisir ijazah dan transkrip nilai. Proses legalisir ijazah dan transkrip nilai yang dilakukan saat ini adalah melalui beberapa tahapan, yaitu alumni yang 
ingin melakukan legalisir harus datang ke kampus terlebih dahulu dengan membawa dokumen berupa ijazah dan nilai asli untuk melakukan pendaftaran, kemudian melakukan pembayaran sesuai dengan jumlah lembar legalisir yang diinginkan. Pihak BAAK kemudian akan menggandakan dokumen tersebut, dan akan menemui Dekan untuk meminta tanda tangan atas dokumen hasil penggandaan tadi. Ketika tanda tangan Dekan sudah didapat, maka BAAK akan membubuhkan stempel basah pada dokumen tersebut. Ketika proses legalisir telah selesai, staf BAAK akan menghubungi alumni untuk memberitahu bahwa dokumen legalisir telah selesai dan alumni sudah bisa kembali lagi ke kampus untuk mengambil dokumen yang telah dilegalisir tersebut. Itu juga jika alumni sempat meninggalkan nomor telpon yang bisa dihubungi. Jika tidak ada nomor telpon yang bisa dihubungi, maka BAAK akan menunggu hingga alumninya sendiri yang menelpon BAAK.

Proses legalisir dengan tahapan ini tidaklah efisien dan menghabiskan banyak waktu, terutama untuk alumni yang sudah bekerja karena harus mendapatkan izin minimal 2 kali dari kantor untuk bisa melakukan legalisir, yaitu pertama pada saat ingin ke kampus untuk melakukan pendaftaran legalisir, dan yang kedua adalah untuk mengambil dokumen hasil dari proses legalisir tersebut. Terlebih lagi jika alumni telah tinggal di luar kota, atau bahkan di luar pulau Jawa. Tentu akan memerlukan biaya transportasi yang tidak sedikit.

Untuk itu dirasa perlu untuk menyediakan alternatif lain bagi alumni dalam melakukan legalisir ijazah dan transkrip nilainya, yaitu dengan membuat sebuah aplikasi berbasis website sebagai bagian dari sistem layanan elektronik (e-services) yang dapat digunakan oleh alumni untuk melegalisir ijazah dan transkrip nilainya. Alumni dapat mengajukan pembuatan legalisir dengan mengupload file hasil scan dari ijazah dan transkrip nilai aslinya. Pada saat mengajukan pembuatan legalisir ini, alumni dapat memasukkan jumlah dokumen legalisir yang diinginkan dan dapat memilih apakah dokumen legalisir yang telah selesai akan diambil sendiri ke kampus atau dikirimkan ke alumninya. Setelah itu alumni melakukan pembayaran sesuai dengan jumlah dokumen yang diinginkan. Kemudian staf BAAK akan memproses pengajuan legalisir tersebut seperti biasa, dan dapat memberikan progres dari tiap tahapan yang dilakukan melalui aplikasi tersebut agar alumni dapat memantau perkembangan dari pengajuan legalisirnya. Ketika dokumen legalisir telah selesai, staf BAAK akan memberikan status selesai pada pengajuan legalisir tersebut, yang akan secara otomatis memberikan notifikasi via email kepada alumni

Ada beberapa penelitian yang telah dilakukan sebelumnya, yang turut mempengaruhi penelitian ini. Berikut ini adalah beberapa penelitian terdahulu yang terkait dengan penelitian ini. Pada penelitiannya, Aulio Romadho Agung berpendapat bahwa sistem informasi dapat mengolah data riwayat pesanan sesuai kebutuhan dengan risiko data hilang lebih kecil daripada metode sebelumnya yang hanya menggunakan kertas. Penelitian ini membuat sebuah sistem informasi yang dapat digunakan untuk membantu proses pemasaran dan pemesanan di Liochita Cleaning. Sistem yang dibuat berbasis web dan mobile dengan menggunakan framework PHP Codeigniter [4].

Penelitian sebelumnya dengan judul Implementasi E-Service Pada Organisasi Publik Di Bidang Pelayanan Publik Di Kelurahan Cibangkong Kecamatan Batununggal Kota Bandung membuat e-service untuk bidang pelayanan publik di Kota Bandung. Berdasarkan hasil penelitian, aplikasi yang dibuat telah memberikan manfaat dan kemudahan bagi warga masyarakat dalam pencatatan data kependudukan. Adapun hambatan yang terjadi adalah tidak tersedianya operator yang bersifat teknis [5]. E-Service juga bisa digunakan untuk informasi potensi pertanian desa di Indonesia. Penerapannya sudah dilakukan oleh Muh Zia Ulkhaq pada penelitiannya yang berjudul Model Layanan Elektronik (eservice) informasi potensi pertanian desa di Indonesia. Penelitian tersebut melibatkan beberapa stakeholder yaitu kelompok tani (pemberi informasi) dan Bulog, Pedagang serta konsumen (penerima informasi). hasil penelitiannya berupa e-service untuk mempermudah konsumen dan pemilik komoditi dalam bertransaksi

Pada penelitian berjudul Pengaruh E-Service Quality Terhadap Kepuasan Pelanggan Sebagai Pengguna Aplikasi PLN Mobile didapat kesimpulan bahwa keberadaan e-service yang baik berpengaruh terhadap kepuasan pelanggan [6]. Penelitian yang berkaitan tentang legalisir ijazah pernah dilakukan oleh Suparman dan Andri Pranolo pada penelitiannya dengan judul Desain Sistem Layanan Online Legalisir Ijazah Dan Transkrip Akademik Di FKIP Universitas Ahmad Dahlan. Hasil dari penelitian mereka berupa perancangan sistem online sebagai media layanan alumni untuk keperluan legalisasi copy ijazah dan transkrip akademik, yang terdiri dari desain basis data dan desain sistem menggunakan Unified Moedelling Language, serta perancangan antar muka halaman utama sistem layanan online (SILON) legalisir ijazah dan transkrip akademik [3].

Penelitian yang dibuat oleh Nur Andula dan Bustami Yusuf membuat e-leges, sebuah sistem legalisir ijazah berbasis online yang memanfaatkan QR Code. QR Code digunakan untuk mencegah pemalsuan dokumen yang marak terjadi [7]. Penelitian lain dengan judul Perancangan Sistem Informasi Permohonan Surat Online "Sipadu" di Tingkat Kecamatan Berbasis Web membuat sebuah sistem agar warga bisa melakukan permohonan surat secara online. Jenis surat yang bisa ditangani oleh aplikasi pada penelitian itu adalah kartu pencari kerja, surat keterangan domisili usaha, sudah keterangan usaha, surat kematian, surat keterangan ahli waris dan surat keterangan domisili tempat tinggal [8].

Penelitian yang dibuat oleh Indra Soraya dan Asep Deddy Supriatna membuat website untuk pemesanan paket wisata garut untuk memudahkan pelanggan yang berasal dari luar kota. Aplikasi yang dibuat bisa digunakan sebagai fasilitas untuk membantu perusahaan dan pelanggan dalam melakukan pemesanan paket wisata. Sistem dibuat menggunakan Bahasa pemrograman PHP dan database MySQL [9]. 
Dengan adanya sistem informasi pelayanan jasa pesta pernikahan di Kampus Dekorasi berbasis website diharapkan mempermudah calon pengantin melakukan pemesanan jasa. Selain itu penyimpanan data menjadi lebih aman karena data akan disimpan ke database. Admin juga dapat mencari data pelanggan lebih mudah [10]. Penelitian berjudul Sistem informasi Pemesanan dan Pembelian Tiket Bus Online Berbasis Web Pada P.O Budiman telah membuat sistem yang dapat memudahkan pelanggan dalam melakukan pemesanan tiket yang akan dijual dibutuhkan sistem pemesanan tiket berbasis web yang dibangun menggunakan bahasa pemrograman PHP dan database MySQL sehingga pelanggan dapat melakukan pemesanan tiket dimana saja dan kapan saja yang dapat diakses 24 jam nonstop tanpa batasan jarak dan waktu [11].

Berdasarkan permasalahan dan penelitian terdahulu, pada penelitian ini akan dibuat sebuah aplikasi berbasis website yang dapat digunakan oleh alumni untuk melegalisir ijazah dan transkrip nilai, sebagai bagian dari peran Universitas Budi Luhur dalam melayani alumninya, di mana pun alumninya berada. Tujuan dari penelitian ini adalah membuat aplikasi berbasis website untuk proses legalisir ijazah dan transkrip nilai. Manfaat dari penelitian ini adalah memudahkan alumni melakukan proses legalisir ijazah, sehingga alumni tidak perlu datang ke kampus untuk melakukan proses legalisir.

\section{METODE PENELITIAN}

\subsection{Metode Penelitian}

Dalam melakukan penenelitian tentu ada langkah-langkah yang akan dilakukan dari awal sampai akhir penelitian yang dituangkan dalam Gambar 1 :

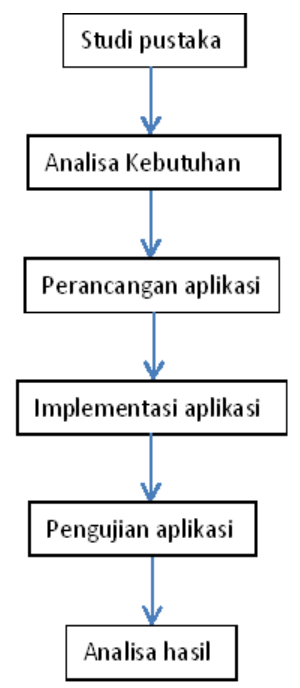

Gambar 1. Metode Penelitian

Penelitian dimulai dengan tahap studi pustaka yang dilakukan dengan cara mengumpulkan, membaca dan juga memahami jurnal, makalah serta referensi lain guna mendapatkwan informasi yang dibutuhkan dalam menunjang penelitian ini. Tahapan berikutnya adalah analisa kebutuhan sehingga bisa diketahui apa saja yang diperlukan dalam membuat aplikasi ini. Dalam tahapan ini juga dilakukan wawancara kepada staf BAAK. Pada tahap perancangan aplikasi dibuatlah gambaran aplikasi yang akan dibuat, pembuatan struktur database dan pemilihan bahasa pemrograman yang digunakan.

Pada tahapan implementasi aplikasi dibuatlah aplikasi berbasis web dengan bahasa program PHP untuk elayanan legalisir ijazah dan transkrip nilai. Pada tahap pengujian aplikasi dilakukan pengujian dari aplikasi yang telah dibuat, serta mengevaluasi apabila masih terdapat kesalahan dan kekurangan. Aplikasi diuji langsung oleh pihak terkait agar bisa mengetahui apakah aplikasi yang dibuat sudah sesuai permintaan atau belum. Tahapan terakhir adalah melakukan analisa hasil dari aplikasi yang dibuat

\subsection{Alat dan Bahan}

Alat dan bahan yang digunakan pada penelitian ini adalah 
a. Hardware yang dipakai dalam pengujian aplikasi ini adalah sebuah laptop dengan spesifikasi Processor Intel i53570, RAM 4 GB DDR3, VGA HD7850 2GB DDR5, Monitor 14” 1920x1080, Keyboard, Mouse dan Harddisk 1 TB.

b. Software yang dipakai dalam pengembang aplikasi ini adalah Sistem Operasi Windows10 64 bit, XAMPP Version 5.6.23 (PHP, Apache, MariaDB), Browser Google Chrome, Library CodeIgniter sebagai framework PHP

\subsection{Data Penelitian}

Data yang digunakan dalam penelitian ini adalah data alumni, data pembayaran legalisir, dan data ijazah serta nilai. Terdapat juga dokumen pendukung yang bisa digunakan sebagai acuan dalam penelitian ini yaitu dokumen pengajuan legalisir dan pengambilan dokumen legalisir yang telah selesai. Berikut ini adalah metode pengumpulan data

\subsection{Metode Pengumpulan Data}

1) Pengamatan (Observasi)

Mengadakan pengamatan langsung ke BAAK Universitas Budi Luhur terkait proses legalisir online saat ini agar data yang dihasilkan lebih lengkap.

2) Wawancara (Interview)

Mengajukan pertanyaan lisan kepada staff BAAK Universitas Budi Luhur untuk mendapatkan data-data yang diperlukan dalam penelitian.

3) Dokumentasi

Metode penelitian dengan cara mengumpulkan dokumen-dokumen terkait yang menjadi objek penelitian.

4) Metode kepustakaan

Metode penelitian dengan cara mengumpulkan referensi dari jurnal dan penelitian sebelumnya.

\section{HASIL DAN PEMBAHASAN}

\subsection{Class Diagram}

Pada Gambar 2 adalah class diagram aplikasi ini

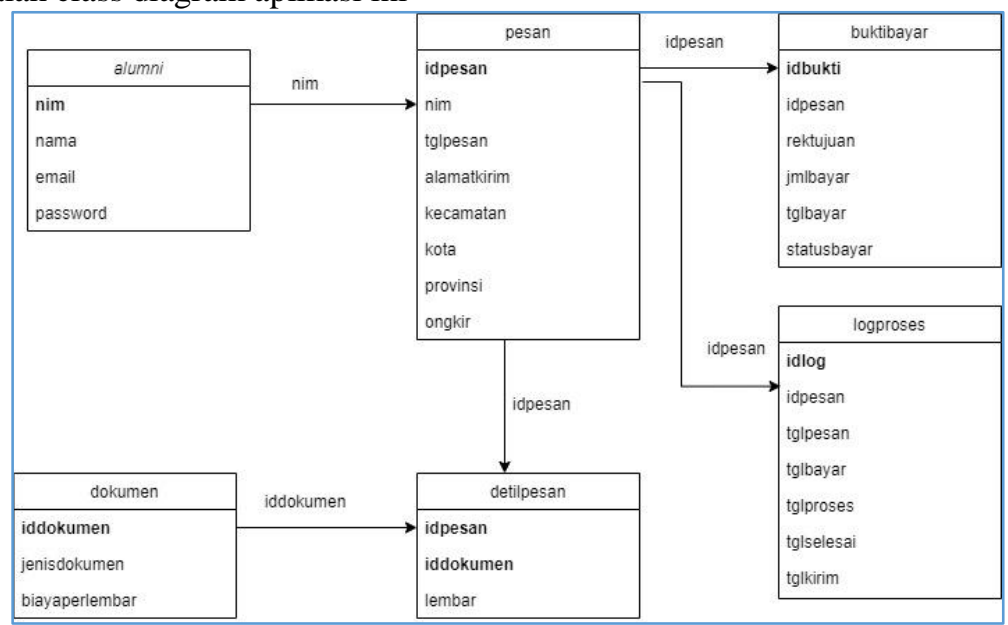

Gambar 2. Class Diagram

Pada Gambar 2 terdapat beberapa tabel yang digunakan pada aplikasi ini, yaitu :

a. Tabel alumni, digunakan untuk menyimpan data alumni.

b. Tabel dokumen, digunakan sebagai master jenis dokumen, misalnya ijazah dan transkrip nilai.

c. Tabel pesan, digunakan untuk menyimpan data pesan legalisir dan alamat pengiriman

d. Tabel detilpesan, digunakan untuk menyimpan detail dokumen yang dipesan dalam suatu pesanan.

e. Tabel buktibayar, digunakan untuk menyimpan data bukti pembayaran.

f. Tabel logproses, digunakan untuk menyimpan proses beserta tanggal 


\subsection{Use Case Diagram}

Ada 2 aktor yang berperan dalam aplikasi ini, yaitu alumni dan admin. Pada Gambar 3 dapat dilihat use case diagram aplikasi ini. Berdasarkan Gambar 3 tersebut, alumni dapat melakukan pemesanan, mendapat notifikasi dari proses legalisir via email, mengirim bukti pembayaran dan melihat status dari pesanan legalisirnya. Di sisi lain, admin atau staf BAAK dapat melihat pesanan, mengupdate proses dan memeriksa bukti pembayaran yang dikirim oleh alumni

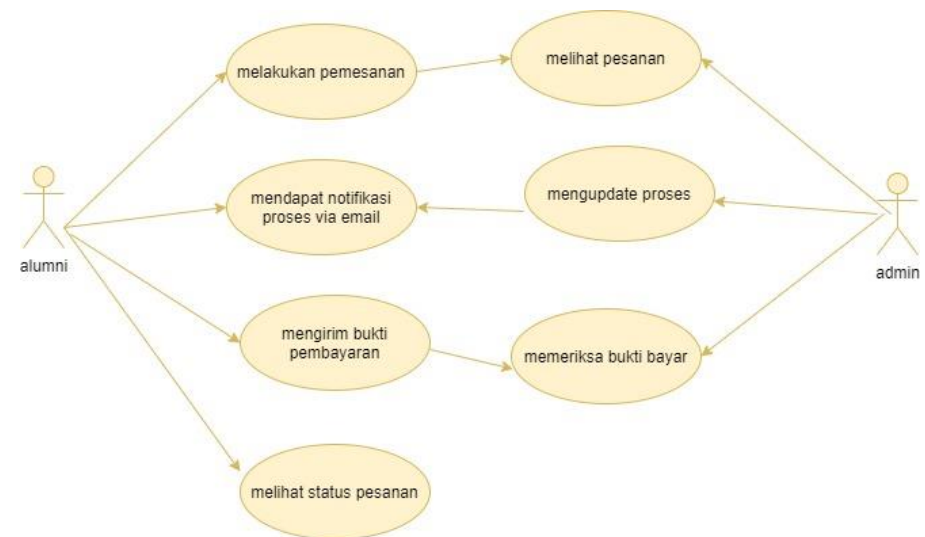

Gambar 3. Use Case Diagram

\subsection{Activity Diagram}

Berikut adalah beberapa activity diagram dalam penelitian ini :

a. Pemesanan Legalisir

Untuk melakukan pemesanan legalisir ijazah, alumni membuka website dan memilih menu legalisir. Pada halaman legalisir, alumni mengisi form pesan yang berisi jenis dokumen yang akan dilegalisir, jumlah, alamat pengiriman hasil legalisir dan upload scan dokumen aslinya. Jika sudah benar, alumni menekan tombol pesan. Dilanjutkan dengan sistem melakukan pengecekan data. Jika data sudah valid, sistem akan menyimpan ke database dan memberikan notifikasi ada order baru kepada admin. Activity diagram pemesanan legalisir bisa dilihat Pada Gambar 4

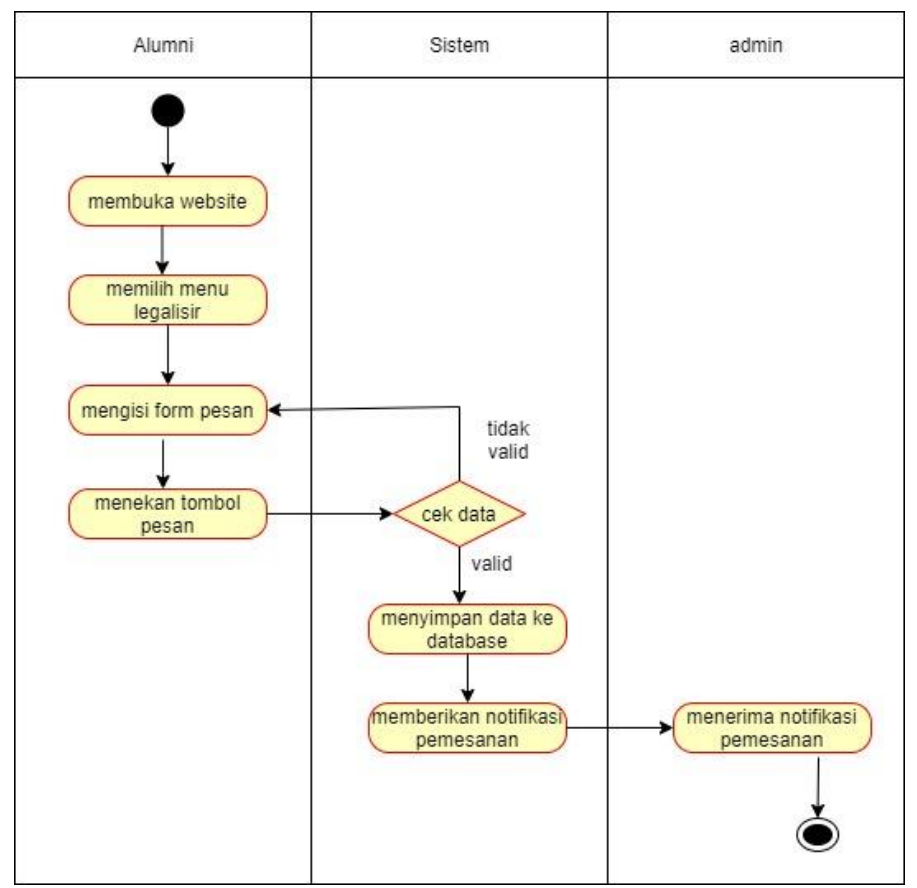

Gambar 4 . Activity Diagram Pemesanan Legalisir

b. Mengirim Bukti Pembayaran 
Setelah melakukan pemesanan, alumni melakukan konfirmasi pembayaran dengan cara masuk ke website dan memilih menu konfirmasi pembayaran. Pada halaman konfirmasi pembayaran, alumni diminta untuk mengisi form yang berisi inputan no pesan, tgl bayar, rekening tujuan, jumlah bayar dan tanggal bayar. Sistem akan melakukan validasi inputan. Jika inputan valid, sistem akan mengirimkan notifikasi email kepada admin. Activity diagram mengirim bukti pembayaran bisa dilihat Pada Gambar 5

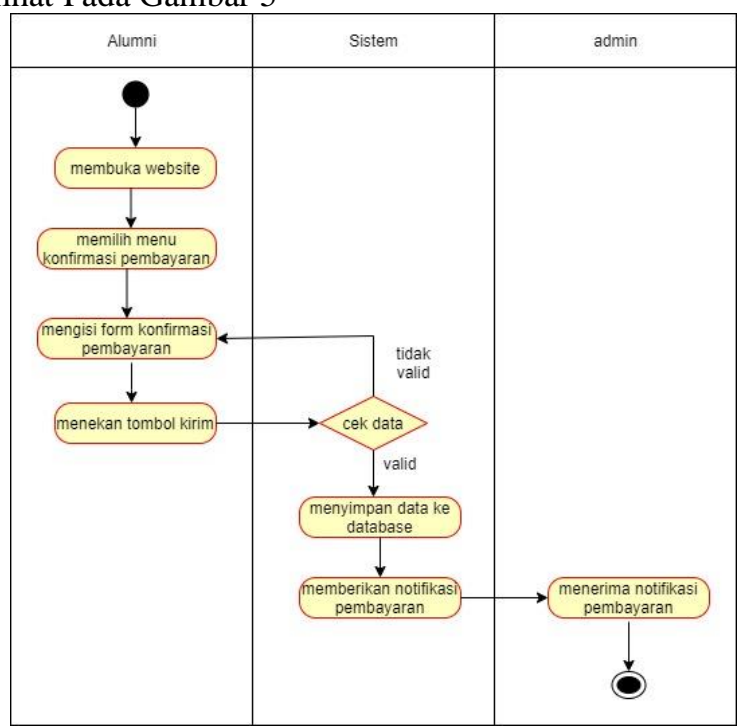

Gambar 5. Activity Diagram Mengirim Bukti Pembayaran

c. Update Proses

Setelah pembayaran dikirim, admin melakukan update proses pelayanan legalisir. Admin membuka halaman admin dan masuk ke menu pemesanan. Pilih salah satu pemesanan yang akan diupdate prosesnya. Update proses yang bisa dilakukan meliputi pemesanan, pembayaran, pemrosesan, selesai dan pengiriman. Setiap kali admin melakukan update proses, sistem akan mengirimkan notifikasi melalui email kepada alumni. Activity diagram update proses bisa dilihat Pada Gambar 6

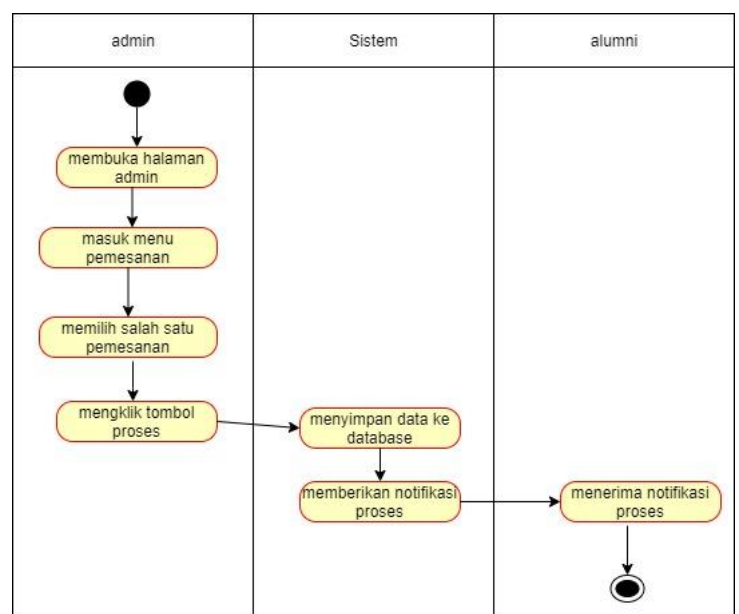

Gambar 6. Activity Diagram Update Proses

\subsection{Tampilan Layar}

Berikut adalah beberapa tampilan layar dari aplikasi berbasis website yang dibuat :

a. Alumni Melakukan Pemesanan Legalisir

Pada Gambar 7 bisa dilihat halaman alumni melakukan pemesanan legalisir, di mana pada layar ini alumni dapat mengupload file hasil scan dari dokumen yang ingin dilegalisir dan jumlah legalisir yang diinginkan. File hasil 
scan bisa berupa file png, jpg dan pdf. Sistem akan menampilkan hasil perhitungan yang harus dibayar alumni berdasarkan jumlah dokumen legalisir. Jika sudah selesai, klik tombol lanjut ke konfirmasi untuk proses berikutnya.

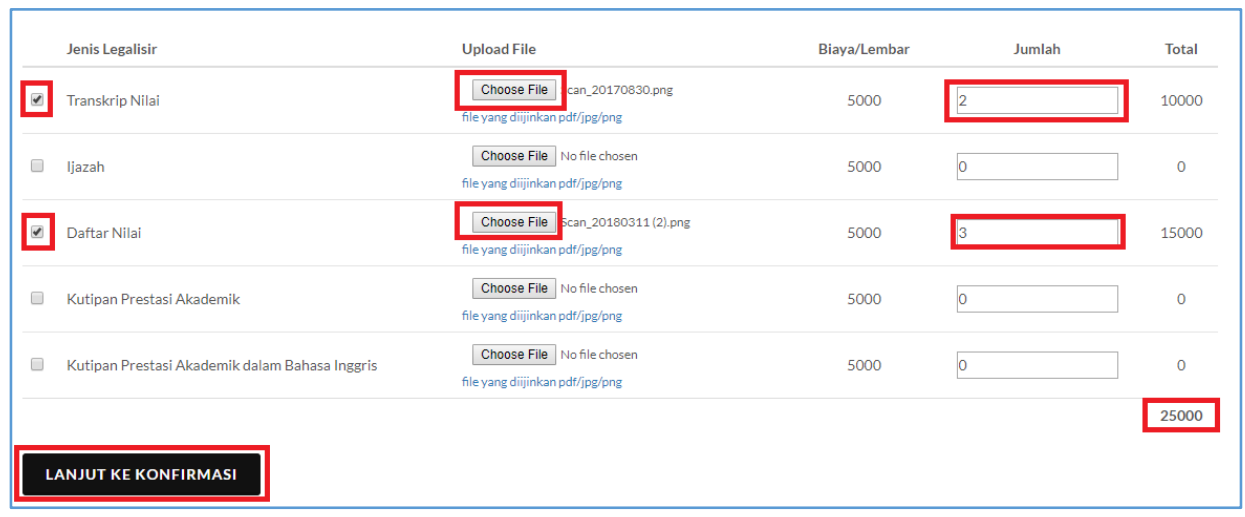

Gambar 7 . Alumni Melakukan Pemesanan Legalisir

\section{b. Alumni Mengirim Bukti Pembayaran}

Pada Gambar 8 dapat dilihat tampilan halaman halaman form untuk melakukan konfirmasi pembayaran. Alumni mengisi no legalisir, nama bank dan nama pemilik rekening yang digunakan untuk transfer. Alumni juga wajib mengisi foto bukti pembayaran untuk memudahkan staf BAAK melakukan valiasi pembayaran. Jika sudah selesai, klik tombol kirim konfirmasi pembayaran. Sistem akan memberikan notifikasi email ke staff BAAK.

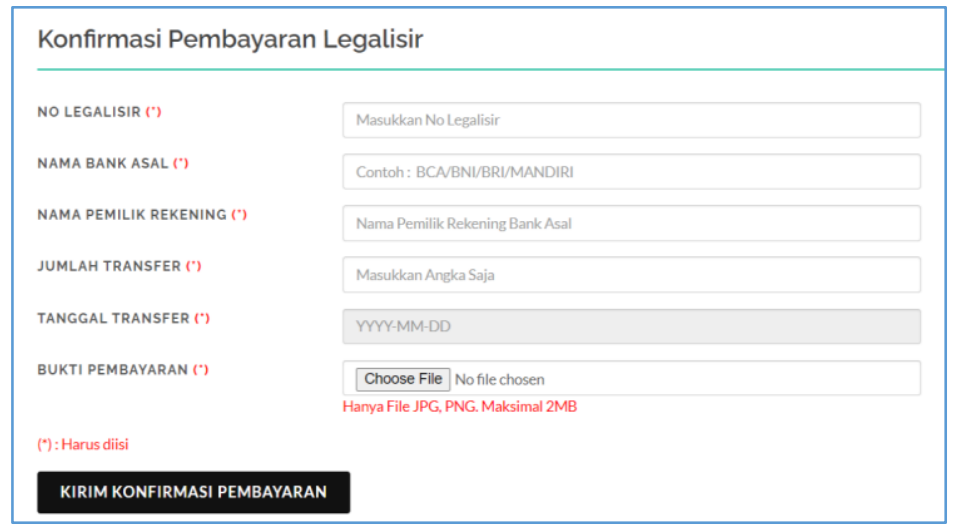

Gambar 8 . Alumni Mengirim Bukti Pembayaran

c. Admin Melihat Pemesanan

Gambar 9 merupakan tampilan halaman admin untuk melihat pemesanan legalisir baru. Pada halaman ini ditampilkan tanggal permintaan legalisir, no legalisir, nim, nama, email, no telp dan total yang harus dibayar. Admin dapat melihat detail legalisir dengan mengklik no legalisir sehingga terlihat dokumen hasil scan yang sudah di upload alumni dan berapa jumlah legalisir yang ingin dibuat. 
available online at http://jom.fti.budiluhur.ac.id/index.php/IDEALIS/index

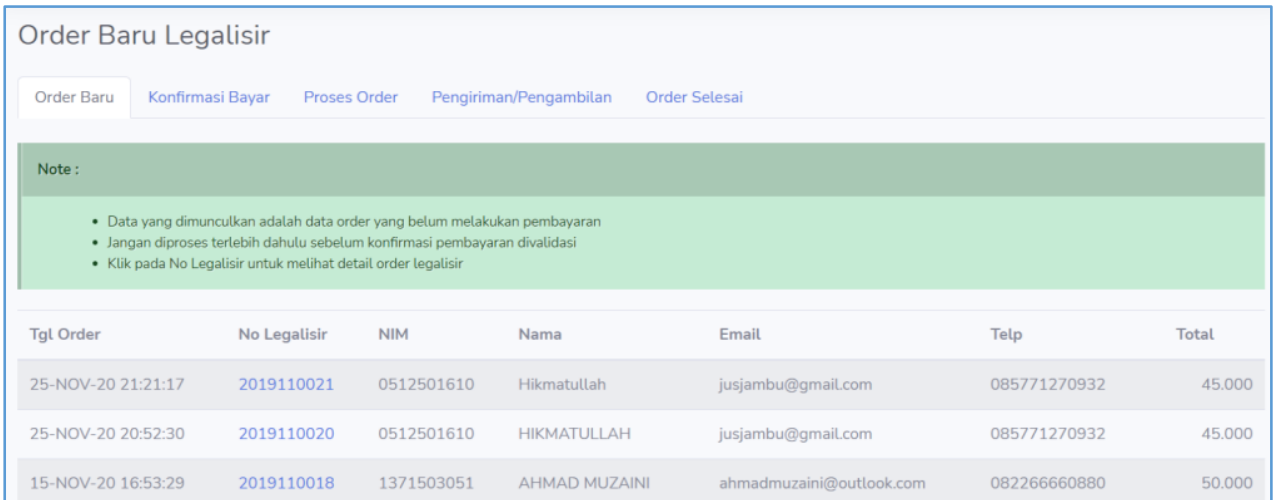

Gambar 9. Admin Melihat Pemesanan

\section{d. Email Notifikasi Update Proses}

Pada Gambar 10 adalah tampilan email notifikasi yang dikirimkan ke alumni. Notifikasi yang dikirim ke alumni adalah pada awal pemesanan legalisir, update proses oleh BAAK dan pada saat proses legalisir selesai. Alumni bisa mengklik tombol cek status legalisir untuk melihat perkembangan proses legalisir.

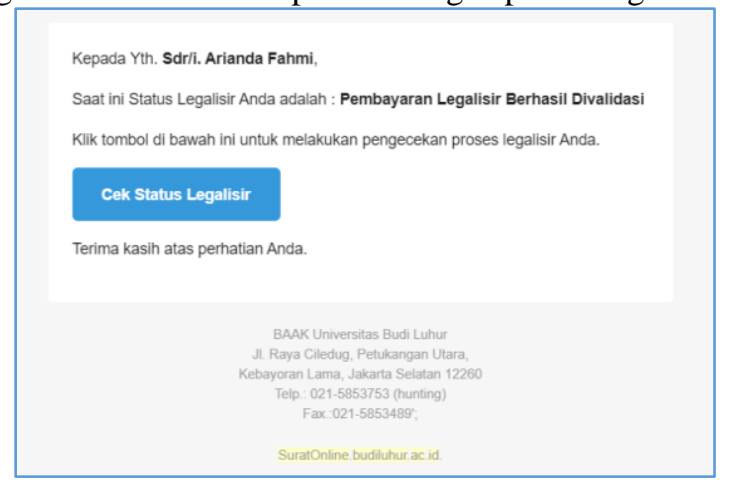

Gambar 10. Email Notifikasi Update Proses

\subsection{Korelasi Masalah dan Solusi}

Pada Tabel 1 bisa dilihat korelasi masalah dan solusi

Tabel 1. Korelasi Masalah

\begin{tabular}{lllll}
\hline No & \multicolumn{1}{c}{ Masalah } & \multicolumn{1}{c}{ Solusi } & \multicolumn{1}{c}{ Modul/Fitur } \\
\hline 1 & $\begin{array}{l}\text { Alumni yang berada di luar kota } \\
\text { kesulitan untuk melakukan } \\
\text { legalisir }\end{array}$ & $\begin{array}{l}\text { Disediakan modul pemesanan legalisir } \\
\text { melalui website }\end{array}$ & Modul pemesanan legalisir online \\
\hline 2 & $\begin{array}{l}\text { Alumni kesulitan melakukan } \\
\text { tracking status proses legalisir }\end{array}$ & $\begin{array}{l}\text { Disediakan modul untuk melakukan } \\
\text { tracking status proses legalisir }\end{array}$ & $\begin{array}{l}\text { Fitur nofitikasi email } \\
\text { Modul cek status legalisir }\end{array}$ \\
\hline 3 & $\begin{array}{l}\text { Proses legalisir ijazah yang ada } \\
\text { saat ini tidak efisien karena } \\
\text { alumni harus datang ke kampus } \\
\text { minimal 2 kali }\end{array}$ & $\begin{array}{l}\text { Disediakan fitur pengiriman hasil } \\
\text { legalisir ke alamat alumni }\end{array}$ & $\begin{array}{l}\text { Fitur memasukkan alamat } \\
\text { pengiriman hasil legalisir }\end{array}$ & \\
\hline 3 & $\begin{array}{l}\text { Staff kesulitan melakukan } \\
\text { pendataan alumni yang } \\
\text { melakukan legalisir }\end{array}$ & $\begin{array}{l}\text { Dibuatkan database untuk menampung } \\
\text { data }\end{array}$ & Modul melihat data permintaan \\
legalisir & & \\
\hline
\end{tabular}

\section{KESIMPULAN}

Berdasarkan penelitian yang telah dibuat, maka didapat kesimpulan sebagai berikut : 
a. Aplikasi ini bisa digunakan untuk mempermudah alumni melakukan legalisir ijazah dan transkrip nilai, di mana pun alumni tersebut berada.

b. Staf BAAK dapat memberikan progres dari pengajuan legalisir, sehingga alumni dapat memantau perkembangan dari pengajuan legalisirnya setiap saat melalui aplikasi yang berbasis website ini.

c. Dengan adanya aplikasi e-service legalisir ini, proses bisnis legalisir dokumen menjadi lebih efisien dan mudah.

d. Staf BAAK bisa melakukan pendataaan alumni yang melakukan legalisir

\section{DAFTAR PUSTAKA}

[1] Databoks, “Jumlah Pengguna Internet di Indonesia Capai $196,7 \quad 2020$. https://databoks.katadata.co.id/datapublish/2020/11/11/jumlah-pengguna-internet-di-indonesia-capai-1967-juta.

[2] M. D. Zericka, "Pengembangan Informasi Di Kabupaten Kutai Kartanegara," eJournal Ilmu Komun., vol. 1, no. 1, pp. 345-361, 2013, [Online]. Available: ejournal.ilkom.fisip-unmul.org.

[3] D. Sistem, L. Online, L. Ijazah, T. Akademik, D. I. Fkip, and U. Ahmad, "Desain Sistem Layanan Online Legalisir Ijazah Dan Transkrip Akademik Di Fkip Universitas Ahmad Dahlan,” J. Inform. Ahmad Dahlan, vol. 8, no. 2, p. 102362, 2014, doi: 10.26555/jifo.v8i2.a2061.

[4] A. R. Agung, R. Kridalukmana, and I. P. Windasari, "Pengembangan Sistem Informasi Pemesanan Layanan Jasa Cleaning Service Berbasis Web Dan Mobile Di Liochita Cleaning Semarang,” J. Teknol. dan Sist. Komput., vol. 4, no. 1, p. 34, 2016, doi: 10.14710/jtsiskom.4.1.2016.34-43.

[5] R. A. Buchari, "Implementasi E-Service Pada Organisasi Publik Di Bidang Pelayanan Publik Di Kelurahan Cibangkong Kecamatan Batununggal Kota Bandung," Sosiohumaniora, vol. 18, no. 3, p. 225, 2016, doi: 10.24198/sosiohumaniora.v18i3.8762.

[6] P. E. Quality, K. Pelanggan, P. Aplikasi, and P. C. Chesanti, "Pengaruh E-Service Quality Terhadap Kepuasan Pelanggan Sebagai Pengguna Aplikasi Pln Mobile,” J. Penelit. Pendidik., vol. 18, no. 1, pp. 10-17, 2018

[7] N. Andula and B. Yusuf, "E-Leges : Sistem Legalisir Ijazah Berbasis Online Pada Fakultas Tarbiyah dan Keguruan, UIN Ar-Raniry," Query, vol. 5341, no. October, pp. 1-9, 2018.

[8] N. Hunaifi, A. B. Hikmah, and A. Nurhasan, "Perancangan Sistem Informasi Pengarsipan Dan Permohonan Surat Online 'Sipadu' Di Tingkat Kecamatan Berbasis Web," JUST IT J. Sist. Informasi, Teknol. Inf. dan Komput., vol. 10, no. 1, pp. 40-51, 2019.

[9] I. Soraya and A. D. Supriatna, "Pengembangan Sistem Informasi Pemesanan Paket Perjalanan Wisata Garut Berbasis Online," J. Algoritm., vol. 14, no. 1, pp. 32-39, 2017, doi: 10.33364/algoritma/v.14-1.32.

[10] L. Mazia, A. C. Rudiana, E. Pujiastuti, and D. Ferdiansyah, "Sistem Informasi Pelayanan Jasa Berbasis Web pada Kampus Dekorasi Bojonggede," vol. 8, no. 4, pp. 22-27, 2019.

[11] J. D. Raharjo, R. Tullah, and H. Setiana, "Sistem Informasi Pem esanan Dan Pembelian Tiket Bus Online Berbasis Web Pada P.O. Budiman,”Sist. Inf. Pemesanan Dan Pembelian Tiket Bus Online Berbas. Web Pada P.O. Budiman, vol. 9, no. 2, pp. 120-125, 2019. 